\title{
Osnabrücker Ehrenmedaille 2012 geht an Dipl.-Ing. Jens Stechmann
}

\author{
Altländer Obstbauer vom Freundeskreis „Hochschule Osnabrück Gartenbau \\ und Landschaftsarchitektur"6 ausgezeichnet
}

\author{
Julia Ludger
}

Online publiziert: 1. Februar 2013

(C) Springer-Verlag Berlin Heidelberg 2012

(Osnabrück, 12. November 2012) Der Altländer Obstbauer Dipl.-Ing. Jens Stechmann hat in diesem Jahr die Osnabrücker Ehrenmedaille des Freundeskreises „Hochschule Osnabrück Gartenbau und Landschaftsarchitektur" erhalten. Am Freitag, dem 09.11.12, bekam er die Auszeichnung im Rahmen der 41. Kontaktstudientage der Hochschule Osnabrück am Standort Haste vom Vorsitzenden des Freundeskreises, Dipl.-Ing. Engelbert Lehmacher, überreicht. (Abb. 1)

Stechmann steht seit zwölf Jahren dem zweitgrößten Obstbauberatungsring Europas, dem Obstbauversuchsring des Alten Landes e. V., vor. Zudem vertritt er seit 2010 als Bundesvorsitzender der Fachgruppe Obst im Bundesausschuss Obst und Gemüse auf der politischen Ebene die Interessen aller deutschen Erwerbsobstbauern. In Zusammenarbeit mit der Landwirtschaftskammer Niedersachsen entwickelte Stechmann zudem das Kompetenzzentrum Obst der Norddeutschen Kooperation im Gartenbau zum heutigen ESTEBURG-Obstbauzentrum Jork - dem obstbaulichen Zentrum für angewandte Forschung, Beratung und Bildung in Norddeutschland.

„Der Diplomingenieur Jens Stechmann weiß als Bewirtschafter eines obstbaulichen Familienbetriebes um die gesellschaftlichen Ansprüche, die sich verschärfenden Produktionsbedingungen und streitet mit Erfolg für die Wettbewerbsfähigkeit deutscher Obstbaubetriebe. Seine persönliche Unabhängigkeit sowie sein Interesse und Engagement für das Gemeinwohl zeichnen das Wirken von Jens Stechmann aus“, so Laudator Dr. Karsten Klopp.

J. Ludger, MA $(\bowtie)$

Hochschule Osnabrück, Geschäftsbereich Kommunikation,

Gebäude AF 0308, Albrechtstraße 30, 49076 Osnabrück,

Deutschland

E-Mail: j.ludger@hs-osnabrueck.de

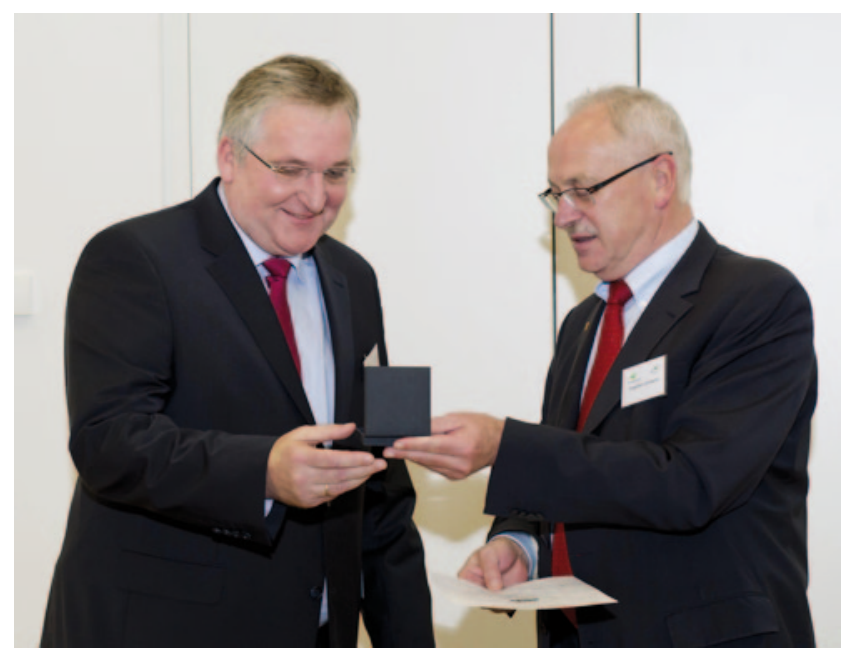

Abb. 1 Ehrenmedaillenträger Dipl.-Ing. Jens Stechmann, der Vorsitzende des Freundeskreises Hochschule Osnabrück Gartenbau und Landschaftsarchitektur e. V., Dipl.-Ing. Engelbert Lehmacher

Preisträger Stechmann erinnerte in seiner Dankesrede an die Anfänge seines beruflichen Werdegangs. „Mein dreijähriges praxisorientiertes Studium an der Hochschule Osnabrück hat die Grundlage für meine vielfältigen beruflichen Aufgaben im Obstbaubetrieb und in den Gremien gelegt.“

Seit 1979 vergibt der Freundeskreis „Hochschule Osnabrück Gartenbau und Landschaftsarchitektur" die Osnabrücker Ehrenmedaille und würdigt damit verdiente Ingenieure des Gartenbaus und der Landschaftsarchitektur. Die Preisträger zeichnen sich dadurch aus, dass sie in besonderer Weise in ihrer beruflichen Tätigkeit hervorgetreten sind und somit den Gartenbau und die Landschaftsarchitektur gefördert haben. 